Research Paper:

\title{
Knowledge of Sexually Transmitted Diseases Among Col- lege Students in the USA
}

\author{
Zahra Amirkhanzadeh Barandouzi ${ }^{1}$ (i) Xiaomei Cong ${ }^{2^{*}}$ (i) \\ 1. School of Nursing, University of Connecticut, Storrs, Connecticut, United States. \\ 2. School of Nursing, University of Connecticut, Storrs, Connecticut, United States.
}

\begin{tabular}{|c|c|}
\hline $\begin{array}{l}\text { Use your device to scan } \\
\text { and read the article online }\end{array}$ & Citation: Amirkhanzadeh Barandouzi, Z., \& Cong, X., 2019. Knowledge of Sexually Transmitted Diseases Among College \\
\hline 口ift? & Students in the USA. Journal of Client-Centered Nursing Care, 5(2), pp. 73-80. https://doi.org/10.32598/JCCNC.5.2.73 \\
\hline forts & doij https://doi.org/10.32598/JCCNC.5.2.73 \\
\hline
\end{tabular}

\section{(c) (1) $\$$}

Article info:

Received: 10 Dec 2018

Accepted: 13 Mar 2019

Published: 01 May 2019

Keywords:

Sexually transmitted diseases, Knowledge, Students, University

\begin{abstract}
A B S T RA C T
Background: Sexually Transmitted Diseases (STDs) are among the most prevalent infectious diseases in young people. The present study assessed the knowledge of STDs among college students.

Methods: This cross-sectional descriptive study that was conducted on 345 undergraduate students at a large public university in the United States. The students were recruited by convenience sampling method. The Sexually Transmitted Disease Knowledge Questionnaire (STD-KQ) was applied in the survey. The study participants responded to the survey anonymously through the Qualtrics online portal. Descriptive statistical analyses were conducted to examine the knowledge levels of the STDs in young adults. Independent Samples t-test and Analysis of Variance (ANOVA) were used to determine the correlation between the knowledge level and demographic data of the subjects. Moreover, SPSS was used for data analysis.
\end{abstract}

Results: In total, 345 undergraduate students aged 18-22 years participated in the present study Among them, 196 (56.8\%) were male. The samples' Mean \pm SD score of STD knowledge was $15.66 \pm 5.84$ (out of 27 points in total). The study participants who previously received sexual education courses achieved higher knowledge scores, compared to the others.

Conclusion: The study results revealed a lack of STD knowledge in young adults. There is a need for conducting educational programs among college students to improve their understanding of STDs etiology and prevention.

\footnotetext{
* Corresponding Author:

Xiaomei Cong, PhD.

Address: School of Nursing, University of Connecticut, Storrs, Connecticut, United States.

Tel: +1 (860) 4862694

E-mail: xiaomei.cong@uconn.edu
} 


\section{Highlights}

- Sexually Transmitted Disease (STDs) are major health challenges facing the world.

- STDs affect people of all ages, specifically young adults during college period.

- College students need more knowledge about STDs etiology and prevention.

\section{Plain Language Summary}

Sexually Transmitted Diseases (STDs) refer to infection transmitted through sexual contact, caused by viruses, bacteria or parasites. STDs are major challenge facing the world. . Young adults, specifically college students, may engage in high-risk sexual behaviors, including having multiple sexual partners and performing unprotected sex. Many STDs occur due to limited sexual health knowledge. The assessment of STD awareness among young adults is essential to develop effective strategies for STD education. The present study aimed to assess the knowledge of college students about STDs. The results indicated the need for conducting educational programs among college students to improve their understanding of STDs etiology and prevention.

\section{Background}

exually Transmitted Diseases (STDs) are major and complicated health challenges facing the world and the United States (U.S.) ((CDC) 2017; Ağaçfidan \& Kohl 1999). The U.S. Centers for Disease Control and Prevention (CDC) reported 20 million new sexually transmitted infections that occur annually in the U.S.; such matter can impose $\$ 16$ billion to the healthcare system ((CDC) 2017). Numerous STDs are often asymptomatic and left untreated or poorly treated. STDs can lead to various health burdens, ranging from physical discomfort and chronic pain to life-threatening health issues, such as ectopic pregnancy, infertility, abortion, stillbirths, malignancy, and even the loss of life. STDs can also increase the risk of acquiring and transmitting the HIV infection (Amu \& Adegun 2015; Control \& Prevention 2015; Ekşi \& Kömürcü 2014; Von Rosen et al. 2018). Due to numerous STDs' health consequences which occur years after the initial infection, having appropriate knowledge regarding primary and secondary STDs prevention is crucial (Eng \& Butler 1997; Von Rosen et al. 2018).

STDs affect people of all ages, specifically young adults ((CDC) 2017; Amu \& Adegun 2015; Baek, Akbar, \& Baguley 2012; Jaworski \& Carey 2007; AL-Malki 2014; Samkange-Zeeb, Mikolajczyk \& Zeeb, 2013). According to the CDC, young adults aged 15-24 years acquire half of all new STDs in the U.S. annually ((CDC) 2017). Youth engage in high-risk sexual behaviors, including having multiple sexual partners and practicing unprotected sex ((CDC) 2017; Amu \& Adegun 2015; Baek et al. 2012; Jaworski \& Carey, 2007; AL-Malki 2014; Samkange-Zeeb et al. 2013). In particular, the transition from high school to college is an indispensable milestone that holds the potential for behavioral changes and opportunities to engage in a variety of risky sexual behaviors; this makes young people vulnerable to the health burdens of STDs (Fromme, Corbin \& Kruse 2008; Reuter, McGinnis \& Reuter 2018). In a study, $50 \%$ of the sexually active college students reported no condom use during sexual intercourse; this finding highlights the role of insufficient knowledge about sexually transmitted diseases (Steinmetz 2013).

Many STDs' complications occur due to limited sexual health knowledge (Baek et al. 2012). Previous international studies reported that college students' awareness of STDs is insufficient.(Ekşi \& Kömürcü 2014; Folasayo et al. 2017; AL-Malki 2014; Subbarao \& Akhilesh 2017). A survey was conducted regarding STDs knowledge among college students in the U.S. Accordingly, the majority of students lacked knowledge about sexual health issues. Moreover, females had higher awareness than men regarding STDs transmission mode (Weinstein, Walsh \& Ward 2008). Engagement in risky sexual behaviors could stem from insufficient knowledge about STDs. In a study, only $43 \%$ of the students reported having access to sexuality education in college (Synovitz et al. 2002). The assessment of STD awareness among young adults is essential to develop effective strategies for STD education (Mou, Bhuiya \& Islam 2015). Increasing the STDs awareness, as the most effective preventive approach, could reduce the rate of people with 
undiagnosed STDs (Masavkar \& Naikwadi 2016; Subbarao \& Akhilesh 2017). The current study will serve as a baseline for subsequent research into the type of sex education which can be provided to college students. The present study aimed to assess the knowledge level on STDs among young adults. The survey outcomes will be a valuable resource for healthcare providers to develop programs, conduct interventions, and educate college students regarding STDs prevention.

\section{Materials and Methods}

This was a cross-sectional descriptive study. An online survey was conducted using the Qualtrics electronic survey portal "www.qualtrics.com", a service authorized by the university. The study population consisted of young adults, who were undergraduate students at a large public university in the northeastern of the U.S. The target population of this survey was registered at the School of Engineering, among the largest schools at the university. Inclusion criteria were students who were $\geq 18$ years old and of all nationalities, ethnicities, and races.

The Sexually Transmitted Disease Knowledge Questionnaire (STD-KQ) was used in this study. The STDKQ was developed by Jaworski and Carey (2007). It measures the respondent' knowledge on 6 sexually transmitted diseases, including HIV, genital herpes, chlamydia, gonorrhea, hepatitis B, and the human papillomavirus. The STD-KQ is a reliable questionnaire with an internal consistency of $\alpha=0.86$ and test-retest reliability of $r=0.88$ (Jaworski \& Carey 2007). It consists of 27 inquiries on the types, symptoms, treatments, and prevention strategies of sexually transmitted diseases. The answer to each item of the questionnaire was identified as 0 or 1. Zero was assigned to a "false" or "do not know" response, and 1 was accredited to the "true" responses. The overall highest score is 27 , which represents a summation of the correct answers. Higher scores signified greater knowledge about STDs.

In addition, a researcher-developed checklist was used to collect the subjects' demographic data, consisting of age, gender, year of college, ethnicity, nationality, and previously taken STDs courses. The Demographic questions were asked at the beginning of the survey. The study protocol was approved by the university Institutional Review Board (IRB). The anonymous survey with the information sheet was emailed to nearly 3000 undergraduate students. The email included a link to the Qualtrics website to allow students to anonymously complete the questionnaire. As a reminder, emails were sent twice to the students' email addresses within 10 days. Once completed, all survey data were collected and downloaded from the Qualtrics website to the researcher's database for further analysis.

The obtained data were downloaded from Qualtrics and analyzed using SPSS. Descriptive statistical analyses were conducted to determine the knowledge levels about STDs among young adults and their demographic data. Additionally, Independent Samples t-test and Analysis of Variance (ANOVA) were used to compare the differences of STDs knowledge with demographic data.

\section{Results}

A total of 345 young adults participated in the current study. Most of them were sophomore students $(n=94$, $27.2 \%)$, aged from 18 to $22(\mathrm{n}=321,93.1 \%)$ years. The majority of study participants were male $(n=196,56.8 \%)$ with American nationality $(n=340,98.5 \%)$. Most of the surveyed students $(n=231,67.2 \%)$ reported no history of attendance to courses related to STD knowledge or prevention. The demographic characteristics of the study participants are presented in Table 1.

The Mean \pm SD total score of the correct answers of the undergraduate students to the STD-KQ was $15.66 \pm 5.84$ (out of 27). Table 2 illustrates the mean score and the frequency of correct answers to the STD questions among the studied students. In Table 2, the questions were listed from the highest correctly answered items to the lowest ones. For example, questions number 11 "the same virus causes all of the STDs" and number 15 "a man must have vaginal sex to get genital warts" got the most correct responses. Questions number 6 (having anal sex increases a person's risk of getting hepatitis B), number 17 (a woman can tell that she has Chlamydia if she has a bad-smelling odor from her vagina), and number 4 (it is easier to get HIV if a person has another STD) got the fewest correct answers.

The studied students' knowledge about the causes of STDs was different. Most of the students $(n=301$, $87.20 \%$ ) knew that the same virus is not the cause of all STDs. Additionally, the majority of study participants $(n=287,83.20 \%)$ believed that having vaginal sex is not the only way of getting genital warts. More than half of the students $(n=223,64.60 \%)$ knew that $\mathrm{Hu}$ man Papillomavirus (HPV) could lead to cancer and the same virus cannot be the cause of HIV, genital herpes, and HPV ( $n=214,62 \%, n=203,58.8 \%, n=187,54.20 \%)$. Half of the students $(n=195,56.50 \%)$ reported that the health problems of STDs are serious for both genders. Moreover, less than half of the students ( $n=163,47.20 \%)$ 
Table 1. Demographic characteristics of the studied college students

\begin{tabular}{ccc}
\hline & Item & No. (\%) \\
\hline Age, $y$ & $18-22$ & $321(93.10)$ \\
& $23-27$ & $18(5.20)$ \\
& Freshman & $6(1.70)$ \\
Year of college & Sophomore & $89(25.80)$ \\
& Junior & $94(27.20)$ \\
Gender & Senior & $77(22.30)$ \\
\hline Previously taken a course & Other & $82(23.80)$ \\
\hline about STD knowledge & Male & $3(0.90)$ \\
\hline & Female & $196(56.80)$ \\
\hline & American & $149(43.20)$ \\
\hline
\end{tabular}

knew that frequent urinary infection cannot be the cause of chlamydia, and less than one third of them $(n=103,29.90 \%)$ believed people with STDs have a greater chance of HIV infection (questions 1, 2, 4, 5, 11, 14, 15, 16, 25), (Table 2).

Regarding the STDs symptoms, most of the students ( $n=279,80.90 \%$ ) knew that a positive HIV test could not determine the severity of HIV symptoms. Furthermore, approximately half of the students $(n=231,67 \%)$ believed that HIV infection cannot develop open sores in the genital area. Also, the majority of them ( $n=241,69.90 \%)$ were aware that STDs cannot be diagnosed just by a person's feeling. For example, more than half of the students $(n=207,60 \%$ ) believed that a woman with gonorrhea could not detect her STD just by her feeling about her body or that a man cannot recognize his Hepatitis B (HB) just by his feeling $(\mathrm{n}=206,59.7 \%)$. Of interest, only one third of the students $(n=120,34.80 \%)$ knew that a bad vaginal odor cannot be a sign of only chlamydia (questions 7, 10, 17, 18, 20, 23), (Table 2). Concerning knowledge about the treatment of STDs, half of the students $(n=193,56.90 \%)$ believed that there is cure for chlamydia. However, less than half of the students $(\mathrm{n}=155,44.90 \%)$ were aware that gonorrhea is curable (questions 3, 8), (Table 2).
The study participant's level of awareness about STD transmission modes was various. Most of the students $(n=231,67 \%)$ knew that genital herpes could be passed from mother to her baby during childbirth. Moreover, half of the students knew that an open sore is not the only way of transferring genital herpes to a sexual partner $(n=191,55.40 \%)$. However, less than half of the students $(n=120,34.80 \%)$ knew that anal sex increases the risk of HB infection (questions 6, 9, 21, 27) (Table 2). Similarly, the students' responses to questions regarding the prevention of STDs were diverse. More than half of the students $(n=225,65.20 \%)$ knew that gonorrhea infection could protect a person from re-infection. Nearly half of the study participants $(n=206,59.70 \%)$ were aware of the vaccination against HB. Interestingly, about half of the subjects knew that there is no vaccination against chlamydia and gonorrhea $(n=189,54.80 \%$, $\mathrm{n}=170,49.30 \%$ ). In addition, half of the students were aware that washing the genital area after sexual intercourse cannot protect a person from genital warts $(\mathrm{n}=189,54.80 \%)$. Additionally, nearly half of the study participants $(n=163,47.20 \%)$ were aware that natural skin condoms (including lambskin) could not protect a person from HIV infection (questions 13, 19, 22, 24, 26, 27), (Table 2). 
Table 2. The frequency and Mean \pm SD score of the correct answers to each question in the STDKQ among 345 respondents

\begin{tabular}{|c|c|c|c|}
\hline & Item & Correct answer No. (\%) & Mean $\pm S D$ \\
\hline 11 & The same virus causes all of the Sexually Transmitted Diseases. & $301(87.20)$ & $0.87 \pm 0.33$ \\
\hline 15 & A man must have vaginal sex to get Genital Warts & $287(83.20)$ & $0.83 \pm 0.37$ \\
\hline 18 & $\begin{array}{l}\text { If a person tests positive for HIV, the test can tell how sick the } \\
\text { person will become }\end{array}$ & $279(80.90)$ & $0.80 \pm 0.39$ \\
\hline 20 & $\begin{array}{l}\text { A woman can tell by the way her body feels if she has a Sexu- } \\
\text { ally Transmitted Disease }\end{array}$ & $241(69.90)$ & $0.69 \pm 0.45$ \\
\hline 9 & $\begin{array}{c}\text { A woman who has Genital Herpes can pass the infection to } \\
\text { her baby during childbirth }\end{array}$ & $231(67.00)$ & $0.66 \pm 0.47$ \\
\hline 7 & $\begin{array}{l}\text { Soon after infection with HIV, a person develops open sores } \\
\text { on his or her genitals (penis or vagina) }\end{array}$ & $231(67.00)$ & $0.66 \pm 0.47$ \\
\hline 24 & $\begin{array}{l}\text { If a person had Gonorrhea in the past, he or she is immune } \\
\text { (protected) from getting it again }\end{array}$ & $225(65.20)$ & $0.65 \pm 0.47$ \\
\hline 14 & Human Papillomavirus (HPV) can lead to cancer in women & $223(64.60)$ & $0.64 \pm 0.47$ \\
\hline 1 & Genital Herpes is caused by the same virus as HIV & $214(62.00)$ & $0.62 \pm 0.48$ \\
\hline 12 & Human Papillomavirus (HPV) can cause Genital Warts & $211(61.20)$ & $0.61 \pm 0.48$ \\
\hline 10 & A woman can look at her body and tell if she has Gonorrhea & $207(60.00)$ & $0.60 \pm 0.49$ \\
\hline 27 & $\begin{array}{l}\text { There is a vaccine that can protect a person from getting } \\
\text { Hepatitis B }\end{array}$ & $206(59.70)$ & $0.59 \pm 0.49$ \\
\hline 23 & A man can tell by the way his body feels if he has Hepatitis B & $206(59.70)$ & $0.59 \pm 0.49$ \\
\hline 5 & $\begin{array}{l}\text { Human Papillomavirus (HPV) is caused by the same virus that } \\
\text { causes HIV }\end{array}$ & $203(58.80)$ & $0.58 \pm 0.49$ \\
\hline 16 & $\begin{array}{l}\text { Sexually Transmitted Diseases can lead to health problems } \\
\text { that are usually more serious for men than women }\end{array}$ & $195(56.50)$ & $0.56 \pm 0.49$ \\
\hline 8 & There is a cure for Chlamydia & $193(56.90)$ & $0.55 \pm 0.49$ \\
\hline 21 & $\begin{array}{l}\text { A person who has Genital Herpes must have open sores to } \\
\text { give the infection to his or her sexual partner }\end{array}$ & $191(55.40)$ & $0.55 \pm 0.49$ \\
\hline 22 & $\begin{array}{l}\text { There is a vaccine that prevents a person from getting Chla- } \\
\text { mydia }\end{array}$ & $189(54.80)$ & $0.54 \pm 0.49$ \\
\hline 26 & $\begin{array}{c}\text { A man can protect himself from getting Genital Warts by } \\
\text { washing his genitals after sex }\end{array}$ & $189(54.80)$ & $0.54 \pm 0.49$ \\
\hline 25 & Human Papillomavirus (HPV) can cause HIV & $187(54.20)$ & $0.54 \pm 0.49$ \\
\hline 19 & $\begin{array}{l}\text { There is a vaccine available to prevent a person from getting } \\
\text { Gonorrhea }\end{array}$ & $170(49.30)$ & $0.49 \pm 0.50$ \\
\hline 2 & Frequent urinary infections can cause Chlamydia & $163(47.20)$ & $0.47 \pm 0.49$ \\
\hline 13 & $\begin{array}{l}\text { Using natural skin (lambskin) condom can protect a person } \\
\text { from getting HIV }\end{array}$ & $163(47.20)$ & $0.47 \pm 0.49$ \\
\hline 3 & There is a cure for Gonorrhea & $155(44.90)$ & $0.44 \pm 0.49$ \\
\hline 6 & Having anal sex increases a person's risk of getting Hepatitis B & $120(34.80)$ & $0.34 \pm 0.47$ \\
\hline 17 & $\begin{array}{l}\text { A woman can tell that she has Chlamydia if she has a bad- } \\
\text { smelling odor from her vagina }\end{array}$ & $120(34.80)$ & $0.34 \pm 0.47$ \\
\hline 4 & $\begin{array}{l}\text { It is easier to get HIV if a person has another Sexually Transmit- } \\
\text { ted Disease }\end{array}$ & $103(29.90)$ & $0.29 \pm 0.45$ \\
\hline
\end{tabular}


For assessing the related factors that may affect the STD knowledge level, the Independent samples t-test and ANOVA were independently conducted. The obtained results indicated no significant difference between STD knowledge level and demographic characteristics, including gender, age, or year of college. However, the STD knowledge level of the students who previously had taken sexual education courses $(16.54 \pm 5.32)$ was significantly different from that of the rest of the participants who received no such training $(15.19 \pm 6.04)$,

\section{Discussion}

The current study examined the knowledge levels regarding sexually transmitted diseases among undergraduate students at a large public university in the northeast of the U.S. The obtained results reflected insufficient awareness among the students in some crucial areas.

Moreover, the findings indicated that the STDs knowledge level was higher in students who had previously taken educational STDs courses. Thus, it is essential to invest in improving the STDs awareness among college students and advance their knowledge of prevention methods. The obtained results are consistent with previous research findings. Different studies by Al-Malki (2014); Ekşi \& Kömürcü (2014); Masavkar \& Naikwadi (2016); Sekirime et al. (2001) and Hashmi et al. (2014) in various countries, including Saudi Arabia, Turkey, India, Uganda, and Pakistan emphasized the inadequate STDs knowledge among college students aged 18-30 years. All of these studies used self-administrated questionnaires for evaluating STD knowledge.

Pereira \& Carmo (2014) in another study in Portugal used the STD-KQ questionnaire, the same questionnaire as applied in the present study, as well as the Sexual Risk Behaviors Questionnaire. Their results indicated insufficient STDs knowledge among young people. Understanding the college student's awareness of STDs is essential for determining the need for educational programs, as a known prerequisite for behavior change. Insufficient STDs knowledge among college students highlights the importance of implementing outreach programs to educate youth for preventing STDs. In the present survey, there was no gender-specific difference in STD knowledge level; however, Samkange-Zeeb (2013) recognized gender as a factor associated with STD awareness in which females had higher knowledge, compared to males. Thus, educational programs must be planned based on the needs of the students.
The present study results indicated that more than half of the students were unaware that natural condoms could not serve as a protection means from HIV. Similarly, AlMalki (2014) documented that most of the subjects were unaware that condoms could not protect one against all STDs. In other words, students in both studies had inadequate knowledge regarding prevention approaches against STDs. This could indicate that the students have a low general awareness of STDs and prevention. Based on the World Health Organization (WHO) report, there is a strong link between STDs and HIV infection. The presence of untreated STDs due to unawareness about transmission mode of STDs could enhance the transmission of HIV by a factor of up to 10 times (Awolade, Cantonment \& Olarewaju 2012). Therefore, education regarding transmission of STDs is essential for the prevention of HIV and other STDs.

Concerning the symptoms of STDs, while there was a misconception about chlamydia symptoms, most of the surveyed students were aware of the symptoms of HIV, $\mathrm{HB}$, and gonorrhea. The findings of the present investigation were similar to those of Al-Malki (2014) in Saudi Arabia, as well as Masavkar and Naikwadi in India, where the best known STD was HIV. Furthermore, in a study in Uganda, Sekirime et al. (2001) found that the knowledge of clinical symptoms of gonorrhea was high among the participants (Sekirime et al. 2001). While pervasive publicity has been given to AIDS/HIV by the media, other STDs have been relatively ignored (Sekirime et al. 2001). The lack of knowledge about clinical features and symptoms of different STDs exposes young generation to danger of short and long-term consequences; many of which are preventable.

Most of the young individuals in the reproductive age are sexually active and engaged in unprotected sexual relationships (Ekşi \& Kömürcü 2014). Statistics suggest that up to $60 \%$ of new STDs occur in people from childhood to adulthood (Masavkar \& Naikwadi 2016). During this transition period, decisions that affect one's future are made. Many young adults enter an active sexual life and engage in risky sexual behaviors without considering its consequences (Ekşi \& Kömürcü 2014). The lower rates of consistent use of prevention methods, such as using condom and changing sexual partners frequently put young people at high risk of catching and transmitting STDs (Von Rosen et al. 2018).

Moreover, young adults are more likely to endure the long-term negative consequences of STDs (Von Rosen et al. 2018). For instance, being infected by an oncogenic HPV can lead to future neoplasia (McCredie et al. 2008). 
Due to the disease burden of STDs, young adults need to be addressed for STD prevention and education provided by public healthcare providers (Reuter et al. 2018; Von Rosen et al. 2018).

Our findings highlighted that the knowledge of STDs in different areas still needs to be addressed among college students. In the present investigation, students had insufficient knowledge regarding STDs, their symptoms, and transmission modes. For example, only $29.9 \%$ of the students knew that HIV infection is easier if a person has another STD. Youth education plays a vital role in shaping the future behavior of the next generation and leads to reducing STDs rates and their socioeconomic burdens. Therefore, collaborative sexual educational programs targetting university students will help young adults to access different aspects of STDs prevention knowledge (Newton-Levinson, Leichliter \& Chandra-Mouli 2016).

Considering further educational interventions in schools is a crucial step to enhance their STDs awareness (AL-Malki, 2014). Adding an educational package in school curricula and holding periodic sessions with healthcare providers at schools could have a lasting and positive effect on students' well-being. However, providing knowledge about STDs should not be limited to schools. STDs awareness can be spread through social media more effectively (Jones, Baldwin \& Lewis 2012). Therefore, the implemention of a multidimensional approach to enhancing youth awareness regarding STDs health issues should be a prime concern of educators. Such approach can include applying different educational programs and interventions for cultivating information and decreasing the risk of infection.

There were several limitations to the current survey that may affect the interpretation of the obtained results. First, the study sample was limited to the undergraduate students at a state university, which may not reflect the complete STDs knowledge level of the entire country. In addition, the convenience sampling method was used, which may not be the representative of the undergraduate students. Additionally, many other studies have applied different questionnaires to evaluate respondents' STDs knowledge, causing difficulty when comparing the reported data. Different questionnaires target different aspects of STDs, which should be considered in the interpretation of the findings. Lastly, the online implementation of the survey might provide the opportunity for students to answer the questions by consulting the online resources that can skew the answers.
This study provided insights on the knowledge level of college students pertaining to STDs symptoms; it is essential for the prevention of various personal and socioeconomic burdens. It was found that college students require further education concerning STDs, common infectious diseases that are entirely preventable. Prevention could occur by increasing the awareness of various types, modes of transmission, and methods of protection. Raising the awareness of the young generation requires developing appropriate STDs training packages and programs. Moreover, engaging social media platforms on STDs awareness can be very effective.

\section{Ethical Considerations}

\section{Compliance with ethical guidelines}

The research protocol of this study was approved by the university's Institutional Review Board. Once the study participants read the invitation to the survey, they had a choice to fill out the questionnaire or not. If they agreed, then they were able to click on the provided link and complete the survey.

\section{Funding}

This research did not receive any specific grant from funding agencies in the public, commercial, or not-forprofit sectors.

\section{Authors' contributions}

Conceptualization: Zahra Amirkhanzadeh Barandouzi, Xiaomei Cong; Methodology: Zahra Amirkhanzadeh Barandouzi, Xiaomei Cong; Investigation: Xiaomei Cong; Writing original draft: Zahra Amirkhanzadeh Barandouzi; Writing-review and editing: Zahra Amirkhanzadeh Barandouzi, Xiaomei Cong; and Supervision: Xiaomei Cong.

\section{Conflict of interest}

The authors declare no conflict of interest.

\section{Acknowledgments}

We would like to thank Dr. Stephen Walsh, the Associate Professor of the University of Connecticut, School of Nursing, for his help and support on the data analysis. 


\section{References}

Al-Malki, B. M., 2014. Knowledge and awareness of sexually transmitted diseases among male university students in Taif Saudi Arabia. International Journal of Medical Science and Public Health, 3(3), pp. 342-9. [DOI:10.5455/ijmsph.2014.070120141]

Awolade, V., Cantonment, F., \& Olarewaju, O. 2012. Prevalence of ulcer forming STIs among HIV-positive women clinic attendees in two Nigerian Hospitals. Retrovirology, 9(1), pp. 151.

Ağaçfidan, A., \& Kohl, P., 1999. Sexually Transmitted Diseases (STDs) in the world. FEMS Immunology $\mathcal{E}$ Medical Microbiology, 24(4), pp.431-5. [DOI:10.1111/j.1574-695X.1999.tb01315.x]

Amu, E. O., \& Adegun, P. T., 2015. Awareness and knowledge of sexually transmitted infections among secondary school adolescents in Ado Ekiti, South Western Nigeria. Journal of Sexually Transmitted Diseases, 2015(260126), 1-7. [DOI:10.1155/2015/260126] [PMID] [PMCID]

Baek, Y., Akbar, H., \& Baguley, G., 2012, December. Relationships and sexual health promotion project for QUT international students. Paper presented at: $23^{\text {rd }}$ ISANA International Education Association Conference Proceedings. 17-19 December 2012, Auckland, New Jersey.

Centers for Disease Control and Prevention, 2017. Sexually transmitted disease surveillance. Retrieved from: https:// www.cdc.gov/media/releases/2017/p0926-std-prevention. html.

Control, C. f., 2015. Reported STDs in the United States: High Burden of STDs Threatens Millions of Americans. Atlanta: Centers for Disease Control and Prevention.

Ekşi, Z., \& Kömürcü, N., 2014. Knowledge level of university students about sexually transmitted diseases. Procedia-Social and Behavioral Sciences, 122, pp. 465-72. [DOI:10.1016/j.sbspro.2014.01.1374]

Eng, T. R. \& Butler, W. T., 1997. The neglected health and economic impact of STDs. Washington: National Academies Press; 1997.

Folasayo, A., et al., 2017. Assessing the knowledge level, attitudes, risky behaviors and preventive practices on sexually transmitted diseases among university students as future healthcare providers in the central zone of Malaysia: A cross-sectional study. International Journal of Environmental Research and Public Health,14(2), pp. 159-73. [DOI:10.3390/ ijerph14020159] [PMID] [PMCID]

Fromme, K., Corbin, W. R., \& Kruse, M. I., 2008. Behavioral risks during the transition from high school to college. Developmen tal Psychology, 44(5), pp. 1497-504. [DOI:10.1037/a0012614] [PMID] [PMCID]

Hashmi, I. A., et al., 2014. Knowledge Regarding Sexually Transmitted Disease Amongst University Students in Pakistan Global Journal of Medical Research, 14(5), pp. 245-68.

Jaworski, B. C. \& Carey, M.P., 2007. Development and psychometric evaluation of a self-administered questionnaire to measure knowledge of sexually transmitted diseases. AIDS and Behavior, 11(4), pp. 557-74. [DOI:10.1007/s10461-006-91685] [PMID] [PMCID]

Jones, K., Baldwin, K. A. \& Lewis, P. R., 2012. The potential influence of a social media intervention on risky sexual behavior and Chlamydia incidence. Journal of Community Health Nurs- ing, 29(2), pp. 106-20. [DOI:10.1080/07370016.2012.670579] [PMID]

Masavkar, S. P., \& Naikwadi, A. M., 2016. Awareness of Sexually Transmitted Diseases [STDs] in College Students. Journal of Contemporary Medicine and Dentistry, 4(2), 15-8.

McCredie, M. R., et al., 2008. Natural history of cervical neoplasia and risk of invasive cancer in women with cervical intraepithelial neoplasia 3: A retrospective cohort study. The Lancet Oncology, 9(5), pp. 425-34. [DOI:10.1016/S1470-2045(08)701037]

Mou, S. Z., Bhuiya, F. A., \& Islam, S. M. S., 2015. Knowledge and perceptions of sexually transmitted diseases, HIV/AIDS, and reproductive health among female students in Dhaka, Bangladesh. International Journal of Advanced Medical and Health Research, 2(1), pp. 9-15. [DOI:10.4103/2349-4220.159118]

Newton-Levinson, A., Leichliter, J. S., \& Chandra-Mouli, V., 2016. Sexually transmitted infection services for adolescents and youth in low-and middle-income countries: Perceived and experienced barriers to accessing care. Journal of Adolescent Health, 59(1), pp. 7-16. [DOI:10.1016/j.jadohealth.2016.03.014] [PMID] [PMCID]

Pereira, H., \& Carmo, A., 2014. Sexually transmitted diseases: Knowledge and perceived prevalence of symptoms in university students. International STD Research E Reviews, pp. 1-11. [DOI:10.9734/ISRR/2014/6850]

Reuter, P.R., McGinnis, S. and Reuter, K.E., 2018. Comparing the awareness of and beliefs in sexually transmitted infections among university students in Madagascar and the United States of America. Peer], 6, p. e4362. [DOI:10.7717/peerj.4362] [PMID] [PMCID]

Samkange-Zeeb, F., Mikolajczyk, R. T., \& Zeeb, H., 2013. Awareness and knowledge of sexually transmitted diseases among secondary school students in two German cities. Journal of Community Health,38(2), pp.293-300. [DOI:10.1007/s10900012-9614-4] [PMID]

Sekirime, W. K., et al., 2001. Knowledge, attitude and practice about sexually transmitted diseases among university students in Kampala. African Health Sciences, 1(1), pp. 16-22.

Steinmetz, K., 2013. condom culture: Why teens aren't practic-ing safe sex. New York: Time Magazine.

Subbarao, N. T. \& Akhilesh, A., 2017. Knowledge and attitude about sexually transmitted infections other than HIV among college students. Indian Journal of Sexually Transmitted Diseases and AIDS, 38(1), pp. 10-4. [DOI:10.4103/0253-7184.196888] [PMID]

Synovitz, L., et al., 2002. Sexual knowledge of college students in a southern state: Relationship to sexuality education. American Journal of Health Studies, 17(4), pp. 163-72.

Von Rosen, F., et al., 2018. STI knowledge in Berlin adolescents. International Journal of Environmental Research and Public Health, 15(1), p. 110. [DOI:10.3390/ijerph15010110] [PMID] [PMCID]

Weinstein, R. B., Walsh, J. L., \& Ward, L. M., 2008. Testing a new measure of sexual health knowledge and its connections to students' sex education, communication, confidence, and condom use. International Journal of Sexual Health, 20(3), p. 212. [DOI:10.1080/19317610802240279] 